\title{
Toxicity study and blood pressure-lowering efficacy of whey protein concentrate hydrolysate in rat models, plus peptide characterization
}

\author{
Fatima A. Hussein, ${ }^{1,2}$ Shyan Yea Chay, ${ }^{1}$ Siti Balqis M. Ghanisma, ${ }^{1}$ Mohammad Zarei, ${ }^{3}$ Shehu M. Auwal, ${ }^{4}$ \\ Azizah A. Hamid, ${ }^{1}$ Wan Zunairah Wan Ibadullah, ${ }^{1}$ and Nazamid Saari ${ }^{1 *}$ \\ ${ }^{1}$ Department of Food Science, Faculty of Food Science and Technology, University Putra Malaysia, 43400 UPM, Serdang, Selangor, Malaysia \\ ${ }^{2}$ Department of Dairy Production, Faculty of Animal Production, University of Khartoum, PO Box 32, Khartoum North 13314, Sudan \\ ${ }^{3}$ Department of Food Science and Technology, Faculty of Applied Sciences, Universiti Teknologi MARA, 40450 Shah Alam, Selangor, Malaysia \\ ${ }^{4}$ Department of Biochemistry, Faculty of Basic Medical Sciences, Bayero University, Kano 700231, Nigeria
}

\section{ABSTRACT}

We evaluated the acute (single-dose) and subacute (repeated-dose) oral toxicity of alcalase-hydrolyzed whey protein concentrate. Our acute study revealed no death or treatment-related complications, and the median lethal dose of whey protein concentrate hydrolysate was $>2,500 \mathrm{mg} / \mathrm{kg}$. In the subacute study, when the hydrolysate was fed at 3 different concentrations (200, 400, and $800 \mathrm{mg} / \mathrm{kg}$ ), no groups showed toxicity changes compared with controls. Then, whey protein concentrate hydrolysate was orally administered to spontaneously hypertensive rats. Results revealed significant reductions in blood pressure in a dose-dependent manner, and dosing at $400 \mathrm{mg} / \mathrm{kg}$ led to significant blood pressure reduction $(-47.8 \mathrm{~mm} \mathrm{Hg})$ compared with controls (blood pressure maintained) and the findings of previous work $(-21 \mathrm{~mm} \mathrm{Hg})$. Eight peptides-RHPEYAVSVLLR, GGAPPAGRL, GPPLPRL, ELKPTPEGDL, VLSELPEP, DAQSAPLRVY, RDMPIQAF, and LEQVLPRD - were sequentially identified and characterized. Of the peptides, VLSELPEP and LEQVLPRD showed the most prominent in vitro angiotensin-I converting enzyme inhibition with halfmaximal inhibitory concentrations of 0.049 and 0.043 $\mathrm{m} M$, respectively. These findings establish strong evidence for the in vitro and in vivo potential of whey protein concentrate hydrolysate to act as a safe, natural functional food ingredient that exerts antihypertensive activity.

Key words: angiotensin-converting enzyme (ACE) inhibition, bioactive peptide, hydrolysis, rat study, whey protein concentrate

Received August 16, 2019.

Accepted November 4, 2019.

*Corresponding author: nazamid@upm.edu.my

\section{INTRODUCTION}

Hypertension is a sustained increase in blood pressure: systolic blood pressure $(\mathbf{B P})>140 \mathrm{~mm} \mathrm{Hg}$ and diastolic BP >90 mm Hg (American Diabetes Association, 2018). Hypertension is a key risk factor in cardiovascular disease, including coronary heart disease, peripheral arterial disease, and stroke. In 2016, the estimated global incidence of hypertension was 17.9 million, and hypertension accounted for $31 \%$ of all deaths worldwide. By 2025, hypertension is projected to affect 1.5 billion people around the world (Kearney et al., 2005). This global increment can be attributed to an aging population that is inadequately equipped for the prevention, diagnosis, and control of the disorder (Olsen et al., 2016). A rise in blood pressure is mainly due to the dual action of angiotensin-I converting enzyme (ACE), which hydrolyzes an inactive decapeptide (angiotensin-I) into a potent vasoconstrictor octapeptide (angiotensin-II) and inactivates the vasodilating nonapeptide bradykinin (Guo et al., 2009). By inhibiting the activity of ACE, the formation of angiotensin-II and the breakdown of bradykinin are halted, keeping BP lower and preventing hypertension (van der Ven et al., 2002).

Current hypertension treatment includes synthetic drugs such as angiotensin receptor blockers, directacting vasodilators, ACE inhibitors, diuretics, calcium channel blockers, and anti-adrenergics. However, these drugs come with side effects such as fatigue, skin rash, headache, constipation, excessive urination, abnormal heart rate, and dizziness. These limitations have encouraged researchers to seek alternatives that are safe and natural, to replace synthetic agents. Positive results have been garnered from the discovery of bioactive peptides derived from various food proteins. One good source of bioactive peptides is whey protein, which demonstrates considerable nutritional and health benefits for humans. Whey peptides have shown antihypertensive (Guo et al., 2009; Tavares et al., 2011; 
Morais et al., 2015), immunomodulatory (Wu et al., 2018), antithrombotic (Silveira et al., 2013), antimicrobial (Boyacı et al., 2016), opiate, and antioxidant properties (Madureira et al., 2010).

In our study, whey protein concentrate (WPC), a manufactured dairy product with a protein content of $76.4 \%$, was chosen to generate bioactive WPC hydrolysate by means of enzymatic hydrolysis using alcalase, followed by in vivo studies exploring the acute toxicity (half-maximal lethal dose; $\mathbf{L D}_{50}$ ), subacute toxicity, and BP-lowering efficacy of WPC hydrolysate, along with characterizing 8 peptide sequences identified from WPC.

\section{MATERIALS AND METHODS}

\section{Materials}

We procured WPC from Purefit Company (Selangor, Malaysia). We procured ACE from rabbit lung and its substrate $N$-hippuryl-His-Leu hydrate powder, from Sigma Chemical Co. (St Louis, MO). We purchased alcalase (EC 3.4.21.62) from Novozymes (Bagsværd, Denmark). Acetonitrile, trifluoroacetic acid and methanol were of HPLC grade. All other chemicals were of analytical grade and were obtained from Fisher Scientific (Waltham, MA) or Merck and Co. (Kenilworth, NJ).

\section{Enzymatic Hydrolysis of WPC}

Alcalase enzyme was mixed with $2.0 \mathrm{~g}$ of WPC at 1:100 ratio (wt/wt) in $100 \mathrm{~mL}$ of borate buffer solution ( $\mathrm{pH} 8)$, and then incubated in a water bath shaker at an agitation rate of $150 \mathrm{rpm}$ and a temperature of $55^{\circ} \mathrm{C}$ to allow optimum hydrolysis as determined previously (data not shown). At the end of hydrolysis, the mixture was placed in boiling water for $10 \mathrm{~min}$ to inactivate the enzyme. After centrifugation at $10,000 \times g$ for 15 min at room temperature, the supernatant was collected and stored at $-80^{\circ} \mathrm{C}$ before freeze-drying. The freeze-dried hydrolysates were used for the acute and subacute toxicity studies, the efficacy studies and the peptide sequencing protocols described below.

\section{Toxicity Study of WPC Hydrolysate Using Wistar-Kyoto Rats}

Acute Toxicity $\left(L D_{50}\right)$. We determined the acute toxicity of WPC hydrolysate using the limit test described by the Organisation for Economic Cooperation and Development (OECD) Test Guideline 425, with slight modifications (OECD, 2011). We performed a limit test because WPC hydrolysate was likely to be nontoxic; it has GRAS (generally recognized as safe) status from the United States Food and Drug Administration (Boland, 2011) under regulation 21CFR184.1979c. Dosing was 2,500 mg $/ \mathrm{kg}$. Before dosing, 5 female Wistar-Kyoto rats with a BW of 150.92 $\pm 2.12 \mathrm{~g}$ (mean \pm standard deviation) were fasted overnight from food, but water was freely available. Female rats were selected, because they are more sensitive to $\mathrm{LD}_{50}$ than male rats (Lipnick et al., 1995). The sample was administered to 1 rat at a time using oral gavage. Each rat was observed carefully for signs of lethality, if any, within the next $48 \mathrm{~h}$. When the rat survived, the next rat was dosed. All 5 rats were tested.

Subacute Toxicity (28 d of Repeated-Dose Feeding). Twenty-eight days of repeated dose feeding was performed according to OECD Test Guideline 407 (OECD, 2008) using Wistar-Kyoto rats aged 8 wk. The animals were randomly divided into 4 groups consisting of 6 males and 6 females each. A control group received distilled water and the treatment groups received WPC hydrolysate at low $(200 \mathrm{mg} / \mathrm{kg})$, intermediate $(400 \mathrm{mg} /$ $\mathrm{kg})$, and high $(800 \mathrm{mg} / \mathrm{kg})$ concentrations. The hydrolysate was dissolved in $1 \mathrm{~mL}$ of distilled water and administered using oral gavage on a daily basis for $28 \mathrm{~d}$. We recorded the BW gain and food and water intake of each rat on a weekly basis throughout the dosing period to observe for early signs of toxicity (data not shown).

At the end of the experiment, all rats were anesthetized with an intraperitoneal injection of ketamine at $80 \mathrm{mg} / \mathrm{kg}$ of BW and xylazine at $8 \mathrm{mg} / \mathrm{kg}$ of BW. A volume of $4.0 \mathrm{~mL}$ of blood was withdrawn from the heart via cardiac puncture and immediately transferred to red Vacutainer tubes (Becton, Dickinson and Company, Franklin Lakes, NJ) that contained coagulant. After standing at room temperature to allow clotting for $30 \mathrm{~min}$, the blood was centrifuged at 1,500 $\times \mathrm{g}$ at $4^{\circ} \mathrm{C}$ for $10 \mathrm{~min}$. The serum was collected as supernatant and kept at $4^{\circ} \mathrm{C}$ until clinical chemistry analysis. The main organs, including the kidney, liver, lungs, and reproductive organs (testes for male rats and ovaries for female rats) were harvested, removed of fats, washed using saline buffer, and kept overnight in $10 \%$ formalin buffer. The formalin was replaced the next day to facilitate blood drainage from organs. For microscopic slides, formalin-soaked organs were cut down the middle into thin pieces in a cross-sectional manner, dehydrated using alcohol, embedded in paraffin, sliced into thicknesses of 4 to $5 \mu \mathrm{m}$, and stained with hematoxylin-eosin dye. All organs from the treatment groups were compared with those of the control group to look for toxicity signs such as cytoplasmic vacuolation, pyknosis/cell necrosis, fading of nucleus, hemorrhage, and swollen cells (Cummings et al., 2012) using a microscope (Nikon Eclipse $50 i$; Nikon Corp., Tokyo, Japan). 


\section{Efficacy Study on WPC Hydrolysate to Reduce Systolic BP in Spontaneously Hypertensive Rats}

We evaluated the BP-lowering efficacy of WPC hydrolysate according to the method described by Fuglsang et al. (2003) and Zou et al. (2014), with some modifications. Male spontaneously hypertensive rats, aged $12 \mathrm{wk}$ and with a mean BW of $238.26 \pm 9.17 \mathrm{~g}$, were divided into 5 groups of 6 animals each: a negative control group (distilled water), a positive control group (captopril $50 \mathrm{mg} / \mathrm{kg}$ ), and 3 treatment groups (alcalase-generated WPC hydrolysate at 200, 400 and $800 \mathrm{mg} / \mathrm{kg}$ BW). The WPC hydrolysate was dissolved in distilled water, thoroughly mixed, and administered to the rats via oral gavage at a standardized volume of $1 \mathrm{~mL} /$ rat. Systolic BP was measured 6 times: a baseline before oral administration $(0 \mathrm{~h})$, and at $2,4,6,8$, and $24 \mathrm{~h}$ after feeding using the CODA tail-cuff method, a noninvasive BP system that allows the identification of pulses at specific rat tail position (Kent Scientific, Torrington, CT). Rats were familiarized with the CODA machine before the experiment. The rats were allowed to move freely into a specially designed restrainer, where their tails were left exposed for cuffing with an occlusive ring. The occlusion cuff was pushed to the base of the tail, and the volume-pressure recording cuff was placed $2 \mathrm{~mm}$ away from the occlusion cuff. Before $\mathrm{BP}$ measurements, the rats were kept on a warming plate $\left(37^{\circ} \mathrm{C}\right)$ for $20 \mathrm{~min}$ to ensure sufficient blood flow inside the tail and increase measurement accuracy. A total of 25 readings were taken per measurement cycle because of large BP variation in each rat. Three readings were then selected to calculate the average BP. All spontaneously hypertensive rats were handled gently and humanely to reduce variations in results due to stress.

\section{Animal Care}

Both Wistar-Kyoto rats and spontaneously hypertensive rats were purchased from the Animal Experimental Unit, Faculty of Medicine, University of Malaya, Kuala Lumpur, Malaysia, and were acclimatized to laboratory conditions for $1 \mathrm{wk}$ before dosing. All rats were housed in plastic cages, in pairs of the same sex, at a temperature of 22 to $24^{\circ} \mathrm{C}$, and with a 12-h light-dark cycle. A standard laboratory diet and tap water were available ad libitum throughout the experiment, except during the acute toxicity study, when fasting was required. All procedures involved in the animal studies were approved by the Institutional Animal Care and Use Committee, Universiti Putra Malaysia (UPM/IACUC/AUP No. R078/2015).

\section{Peptide Sequencing Assay}

Before sequencing, peptides were separated using reversed-phase HPLC and an isoelectric focusing point technique to obtain fractions with less complexity. The fractions demonstrating significantly higher ACE inhibition were then selected for sequencing. During reversed-phase HPLC, the hydrolysate was mixed with deionized water $(100 \mathrm{mg} / \mathrm{mL})$, filtered, and loaded onto a C-18 semi-preparative column $(9.4 \times 250 \mathrm{~mm}, 5$ $\mu \mathrm{m}$; Agilent Technologies, Santa Clara, CA). Chromatography was performed using 0-10 min 100\% mobile phase A ( $0.1 \%$ trifluoroacetic acid in deionized water), followed by gradient elution of mobile phase B $(0.1 \%$ trifluoroacetic acid in acetonitrile) between 10 and 55 min to achieve $58.8 \%$ acetonitrile and holding at $58.8 \%$ acetonitrile for 55-67.5 min. Elution was monitored at $205 \mathrm{~nm}$. During isoelectric focusing separation, the sample was diluted with deionized water to reach a final volume of $1.8 \mathrm{~mL}$. A gel strip with a $\mathrm{pH}$ gradient between 3 and 8 was rehydrated using deionized water. Then, $150 \mu \mathrm{L}$ of the diluted sample was dispensed into individual wells, and a cover seal was placed on top to prevent sample evaporation. A high voltage (500-4,000 V) was applied to both ends of the gel strip to allow peptides to migrate and reside at their respective pI. Upon completion, samples were retrieved from the liquid phase in each well with different $\mathrm{pH}$.

Peptide sequencing was done using tandem mass spectrometry (MS/MS) as previously described (Zarei et al., 2015). Briefly, potent peptide fractions were freeze-dried and reconstituted with $10 \mu \mathrm{L}$ of mobile phase A (0.1\% formic acid in deionized water), and then spun intermittently at $9,750 \times g$ for 15 min to ensure any insoluble material was pelleted at the bottom of the tube. The supernatant was analyzed using a chip-based nanospray liquid chromatography unit (1200 HPLC-Chip/MS Interface; Agilent Technologies) coupled with an accurate mass quadrupole-time of flight mass spectrometer (Q-TOF; 6520, Agilent Technologies). One microliter of sample was injected onto a HPLC analytical chip (C-18; 160-nL enrichment column; $75 \mu \mathrm{m} \times 150 \mathrm{~mm}$ ) and separated with a gradient elution of mobile phase B $(0.1 \%$ formic acid in $90 \%$ acetonitrile) from 3 to $50 \%$ over 30 min. Peptide molecules were then passed through an electrospray ionization source, ionized in positive mode, and fed into a Q-TOF mass spectrometer. Peptides were monitored at a user-defined mass:charge ratio between 110 and $3,000 \mathrm{~m} / z$ (MS scan) and were automatically selected for fragmentation into product ions (MS/MS scan, userdefined $m / z$ between 50 and 3,000) by collision-induced dissociation, based on a precursor absolute threshold 
of 200 counts, precursor charge state selection, and preference at $\mathrm{Z}=1,2,3$, and $>3$, excluding $\mathrm{m} / \mathrm{z}$ $922.009798(\mathrm{Z}=1)$ and $121.050873(\mathrm{Z}=1)$, because both were reference ions. Raw sample data obtained from Q-TOF were searched against the animal species subdirectory of the Swiss-Prot protein database (http: //www.uniprot.org/) using the PEAKS studio 6.0 search engine (Bioinformatics Solution Inc., Waterloo, ON, Canada). Database searching was performed using the following parameters: minimum false discovery rate, $-10 \lg \mathrm{P}$ confidence score greater than 20 (a cut-off value to select peptides of high confidence), and "no enzyme" selection, because the alcalase enzyme was not specified. De novo sequencing was conducted according to the following cutoffs: average confidence score higher than $80 \%$ for at least 4 consecutive amino acids, and a fragment ion mass tolerance of 0.1 Da. Residues of high confidence, labeled in red and blue, were selected for synthesis.

\section{Half-Maximal Inhibitory Concentration for ACE-Inhibitory Peptides}

Eight potentially potent peptide samples were chemically synthesized by a commercial peptide supplier (GenScript, Piscataway, NJ) at a final purity of greater than $90 \%$. We determined half-maximal inhibitory concentration $\left(\mathbf{I C}_{\mathbf{5 0}}\right)$ for these peptides using a combined method from 2 previous studies (Cushman and Cheung, 1971, Ferreira et al., 2007), with certain modifications. Peptide stock solutions were diluted to different concentration ranges of 0.015 to $40 \mathrm{mM}$. The ACE was prepared as stock solution using potassium phosphate buffer $(0.01 M, \mathrm{pH} 7.0)$ and stored at $-80^{\circ} \mathrm{C}$ until use. On the experiment day, the ACE was further diluted to $100 \mathrm{mU} / \mathrm{mL}$ using sodium borate buffer $(\mathrm{pH} 8.3)$. A substrate solution containing $5 \mathrm{~m} M$ HHL and $0.3 M$ $\mathrm{NaCl}$ in $0.1 M$ sodium borate buffer ( $\mathrm{pH} 8.3$ ) was prepared. The assay was initiated by mixing $10 \mu \mathrm{L}$ of peptide with $10 \mu \mathrm{L}$ of $\mathrm{ACE}$ for $10 \mathrm{~min}$ to allow inhibition, followed by the addition of $50 \mu \mathrm{L}$ of substrate solution. The mixture was incubated for $60 \mathrm{~min}$ at $37^{\circ} \mathrm{C}$. The enzymatic reaction was terminated by introducing 75 $\mu \mathrm{L}$ of $1 \mathrm{M} \mathrm{HCl}$. After the reaction was halted, $150 \mu \mathrm{L}$ of pyridine and $75 \mu \mathrm{L}$ of benzene sulfonyl chloride were added. The solution was vortexed for $1 \mathrm{~min}$ and cooled on ice. After cooling, $200 \mu \mathrm{L}$ solution was transferred to the 96-well plate for absorbance measurements at 410 $\mathrm{nm}$. The experiment was carried out in triplicate. The ACE inhibition was calculated as follows,

$$
\text { ACE inhibition }(\%)=\left[\frac{C-S}{C-B}\right] \times 100 \text {, }
$$

where $C$ represents the control absorbance $(\mathrm{ACE}+$ substrate), $S$ signifies the sample absorbance (peptide + $\mathrm{ACE}+$ substrate), and $B$ denotes the blank absorbance (substrate only). The $\mathrm{IC}_{50}$ values were then calculated by fitting the data into nonlinear regression from a plot of ACE inhibition (\%) versus peptide concentration $(\mathrm{m} M)$ using GraphPad Prism 6 (GraphPad Software Inc., San Diego, CA).

\section{Statistical Analysis}

Using Minitab version 16 (Minitab Inc., State College, PA), statistical analysis and comparison between groups were obtained via one-way ANOVA. Tukey's test was used to identify differences between treatments at the $5 \%$ significance level $(P \leq 0.05)$. Data are presented as mean \pm standard deviation from at least 3 determinations.

\section{RESULTS AND DISCUSSION}

\section{Acute and Subacute Toxicity of WPC Hydrolysate}

Acute and subacute toxicity provides crucial information that dictates the safety of materials intended for animal or human use. We evaluated the acute oral toxicity of WPC hydrolysate using the limit test procedure, and the results showed that after dosing 5 female Wistar-Kyoto rats with 2,500 mg hydrolysate $/ \mathrm{kg} \mathrm{BW}$, no animals showed any sign of toxicity and survived the 48-h study period. The $\mathrm{LD}_{50}$ for WPC hydrolysate was greater than $2,500 \mathrm{mg} / \mathrm{kg}$, indicating that the sample was relatively nontoxic (i.e., showing no toxicity when dosed below 2,500 mg/kg; OECD, 2011). In the 28-d repeated-dose subacute study, male and female Wistar-Kyoto rats fed at WPC hydrolysate concentrations of 200,400 , and $800 \mathrm{mg} / \mathrm{kg}$ of BW demonstrated no toxicity signs, further supporting the safety of WPC hydrolysate for human consumption. Body weight gain, food and water intake, relative organ weight, clinical chemistry parameters, and histopathology assessments during the subacute study are reported below.

$B W$, Food Intake, Water Intake, and Relative Organ Weights. Continuous BW loss, reduced appetite, and fluid intake are signs of toxic effects. In the current study, male and female Wistar-Kyoto rats in all treated groups recorded BW increments during the 28 -d dosing period. For male rats, the group receiving intermediate WPC hydrolysate concentration (400 mg/ $\mathrm{kg}$ ) showed significantly lower BW gain from wk 0 to 2 than the control group, but from wk 2 to 4 , the same group of rats showed a BW gain of no significant difference from the controls. The BW gained for female 
rats in all experimental groups were not significantly different from controls in all weeks. In terms of food and water intake, male rats generally showed higher consumption than female rats due to their larger body size, which required more nutrients to support movement and basal metabolic activity. Food intake in male rats was significantly lower during wk 1 and 4 in the 200 and $400 \mathrm{mg} / \mathrm{kg}$ groups; food intake in female rats was lower during wk 1 and 2 in the 400 and $800 \mathrm{mg} /$ $\mathrm{kg}$ groups. Male rats showed lower water intake during wk 4 in the 200 and $400 \mathrm{mg} / \mathrm{kg}$ groups, and female rats showed significantly higher water consumption during wk 0 and 2 in the $200 \mathrm{mg} / \mathrm{kg}$ group, all compared with control (data not shown). All rats were active and healthy and showed no toxic signs, changes in locomotor activity, or behavior during the 28-d study period. The irregular fluctuations in BW gain and food and water intake was likely due to random factors and was irrelevant to the experiment.

We harvested the organs (lung, liver, kidney, testis, and ovary) of the Wistar-Kyoto rats and reported organ weights relative to $\mathrm{BW}$. The ratio of organs to $\mathrm{BW}$ was important for explaining differences between the treatment groups and controls, because normalization of organ weight and BW removes any variation because of different BW in individual rats. This approach is supported by many recent works, which reported relative organ weights when evaluating toxicity from lavender essential oil (Mekonnen et al., 2019), lipophilized phenolic compound (Martínez et al., 2018), and herbal plants (Porwal et al., 2017). Figure 1 depicts the relative organ weights for male and female rats. In both sexes, the liver was the heaviest organ, because the liver carries out the principal detoxification processes in the body. The absolute organ weight for male rats was generally higher than that for females (data not shown), because of the larger body size of male rats. Statistically, both male and female rats revealed no significant differences from controls for all organs. We detected no abnormal organ enlargement or shrinkage in the treatment groups fed WPC hydrolysate.

Clinical Chemistry Analysis. As part of the toxicity study, blood was withdrawn to measure biochemical markers that dictate fluctuations in metabolic and physiological function in multiple organs, because blood is the major circulatory medium responsible for transporting nutrients, waste and toxic substances (if any) to excretion sites. Any adverse effects from testing could be easily detected from blood.

We measured levels of alanine transaminase, aspartate transaminase, alkaline phosphatase, total protein, albumin, total bilirubin, creatinine, urea, cholesterol, triglycerides, and electrolytes $\left(\mathrm{Na}^{+}, \mathrm{Cl}^{-}, \mathrm{K}^{+}, \mathrm{Ca}^{2+}\right)$. Different markers are indicative of damage of different organs. Alanine transaminase, aspartate transaminase and alkaline phosphatase are primarily intracellular liver enzymes. When the liver is injured, these enzymes leak into the bloodstream, leading to elevated levels in the blood, as detected from clinical chemistry analysis. Total bilirubin, cholesterol, and triglycerides are also liver markers: high bilirubin (the breakdown product from old red blood cells) is indicative of impaired liver function, and high cholesterol and triglycerides are indicative of fatty liver. Creatinine and urea are markers of kidney function. Creatinine and urea, both waste products from cell metabolism, are excreted via kidney. High levels of creatinine and urea in the blood show retention of waste products in the body and reflect impaired kidney function. Electrolytes are also directly related to renal function, because their concentration is highly regulated by the kidney via osmotic pressure and water-ion ratio. Total protein and albumin are indicators of liver and kidney function. Lowered protein and albumin levels show liver and kidney malfunction, because they reflects the liver's inability to synthesize protein and the kidney's failure to retain synthesized protein, causing protein excretion from the body as urine.

Table 1 depicts the clinical chemistry parameters for male and female rats fed WPC hydrolysate at different concentrations. For male rats, all treatment groups showed no significant difference $(P>0.05)$ from controls in the measured parameters, including electrolytes, enzyme markers, and plasma compounds (total protein, albumin, bilirubin, creatinine, urea, cholesterol, and triglycerides). Similarly, we detected no significant difference in female rats, except in potassium and cholesterol. Potassium levels in the $800 \mathrm{mg} /$ $\mathrm{kg}$ group and cholesterol levels in the $200 \mathrm{mg} / \mathrm{kg}$ group were significantly lower than controls, at $4.26 \pm 0.25$ $\mathrm{mmol} / \mathrm{L}$ and $2.23 \pm 0.05 \mathrm{mmol} / \mathrm{L}$, respectively. According to the clinical chemistry database for laboratory rats (Boehm et al., 2007; Giknis and Clifford, 2008), the reference levels for potassium and cholesterol are 3.3 to $4.9 \mathrm{mmol} / \mathrm{L}$ and 0.7 to $2.5 \mathrm{mmol} / \mathrm{L}$, respectively. Although the experimental data deviated from the controls, they were still within the normal range and thus were of no toxicological significance. It is common to observe large variations in the clinical chemistry of rats, because individual rats have different physical activity levels, emotional behaviors, stress levels, and diet patterns, which cause biochemical values to fluctuate.

Based on our findings for BW, food and water intake, relative organ weights and clinical chemistry analysis, WPC hydrolysate produced no signs of toxicity in male and female Wistar-Kyoto rats. It is apparent that WPC hydrolysate is nontoxic, a finding that was further confirmed by our histopathological observations, below. 

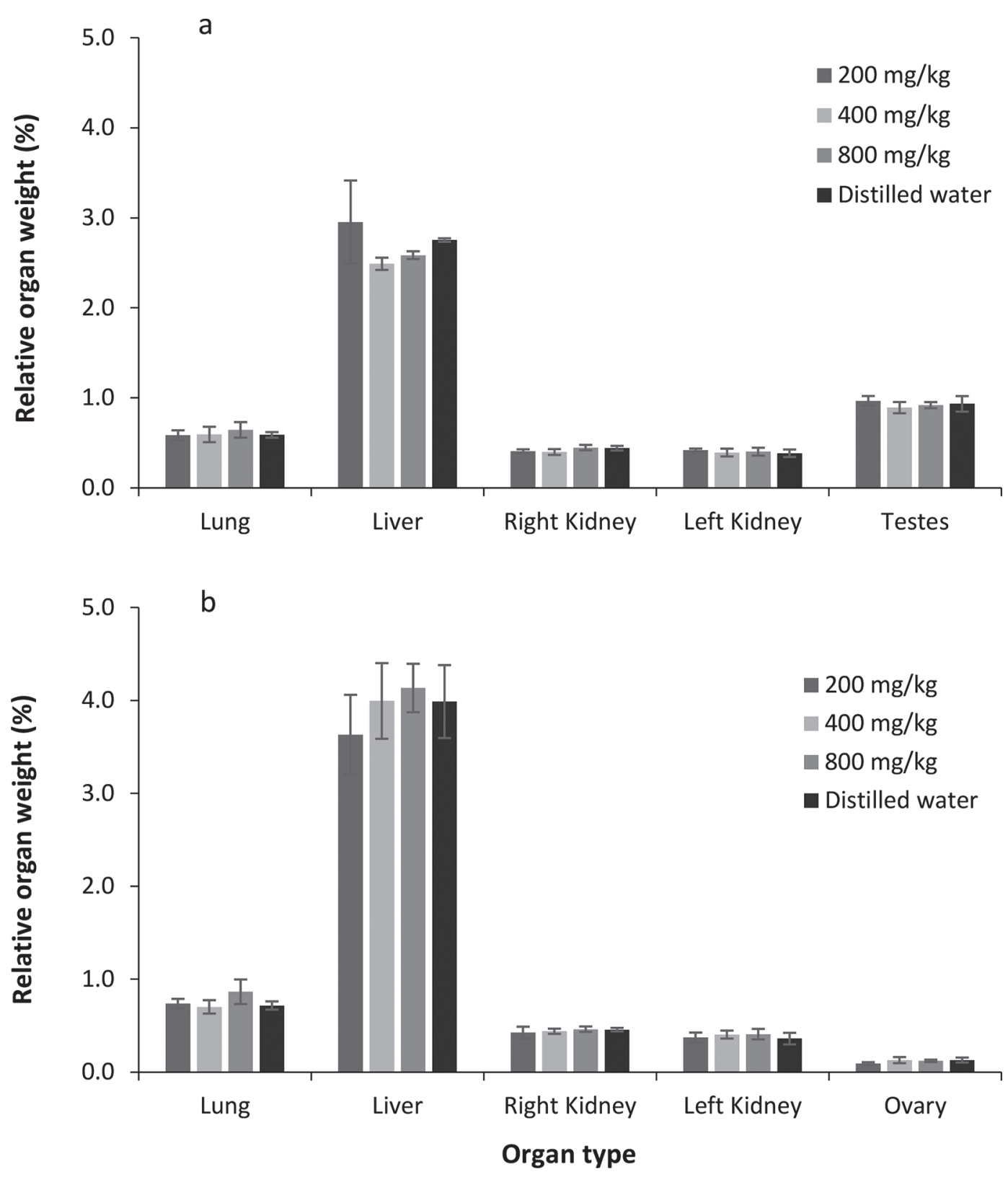

Figure 1. Relative organ weights (\%) for (a) male, and (b) female Wistar-Kyoto rats, subjected to necropsy after oral gavage with whey protein concentrate hydrolysate [0 (distilled water), 200,400 , or $800 \mathrm{mg} / \mathrm{kg}]$ for $28 \mathrm{~d}$. Error bars represent standard deviations for 6 rats $(\mathrm{n}=6)$.

Histopathological Study. Exposure of animals to a test substance for $28 \mathrm{~d}$ is usually sufficient to detect over $90 \%$ of adverse effects (Greaves, 2012). These effects are conveniently confirmed by histopathological evaluation, and the findings provide crucial safety information. Histopathological studies are performed to evaluate the effect of a test substance on vital organs, at the cellular level. Along with regular observations and clinical chemistry analysis, histopathological studies provide essential information about the overall toxicity of a compound.
In the current study, we harvested 5 organs: lung, liver, kidney, testis, and ovary. We monitored the lung for toxic effects affecting the respiratory system. We monitored the liver and kidney because they represent the major filtration and detoxification organs in the body and are exposed the highest amount of toxic substances from oral ingestion. We evaluated the testis and ovary for signs of toxicity in the reproductive system. Our results showed that all organs were normal and displayed no abnormalities compared with controls (Figures 2 and 3). For lung, both control and 
Table 1. Serum biochemical values for male and female Wistar-Kyoto rats fed with whey protein concentrate hydrolysate (at 0 , 200, 400, or $800 \mathrm{mg} / \mathrm{kg}$ ) and killed after $28 \mathrm{~d}^{1}$

\begin{tabular}{|c|c|c|c|c|}
\hline Variable & Control & $200 \mathrm{mg} / \mathrm{kg}$ & $400 \mathrm{mg} / \mathrm{kg}$ & $800 \mathrm{mg} / \mathrm{kg}$ \\
\hline Sodium $(\mathrm{mmol} / \mathrm{L})$ & $141.33 \pm 2.52$ & $143.33 \pm 1.53$ & $145.00 \pm 3.61$ & $143.00 \pm 1.00$ \\
\hline Calcium $(\mathrm{mmol} / \mathrm{L})$ & $2.46 \pm 0.11$ & $2.30 \pm 0.34$ & $2.30 \pm 0.10$ & $2.43 \pm 0.15$ \\
\hline Alanine aminotransferase (U/L) & $42.33 \pm 5.13$ & $54.00 \pm 12.49$ & $47.66 \pm 2.51$ & $46.33 \pm 0.57$ \\
\hline Aspartate aminotransferase (U/L) & $185.00 \pm 9.46$ & $183.67 \pm 2.08$ & $185.00 \pm 4.85$ & $181.33 \pm 1.53$ \\
\hline Albumin $(\mathrm{g} / \mathrm{L})$ & $31.36 \pm 2.27$ & $29.46 \pm 5.65$ & $29.93 \pm 1.68$ & $31.93 \pm 1.70$ \\
\hline Total bilirubin $(\mu \mathrm{mol} / \mathrm{L})$ & $5.66 \pm 0.55$ & $4.76 \pm 0.92$ & $5.10 \pm 0.52$ & $5.23 \pm 1.07$ \\
\hline Creatinine $(\mathrm{mmol} / \mathrm{L})$ & $51.33 \pm 8.50$ & $42.33 \pm 8.32$ & $44.66 \pm 4.72$ & $47.33 \pm 1.15$ \\
\hline Urea $(\mathrm{mmol} / \mathrm{L})$ & $6.43 \pm 0.68$ & $4.83 \pm 1.33$ & $7.43 \pm 1.70$ & $6.26 \pm 0.20$ \\
\hline Cholesterol (mmol/L) & $2.03 \pm 0.05$ & $2.06 \pm 0.35$ & $2.33 \pm 0.65$ & $2.13 \pm 0.40$ \\
\hline Triglycerides $(\mathrm{U} / \mathrm{L})$ & $0.39 \pm 0.01$ & $0.53 \pm 0.10$ & $0.58 \pm 0.16$ & $0.94 \pm 0.19$ \\
\hline \multicolumn{5}{|l|}{ Female rats } \\
\hline Aspartate aminotransferase (U/L) & $222.33 \pm 9.24$ & $207.67 \pm 20.11$ & $196.67 \pm 6.35$ & $203.33 \pm 12.01$ \\
\hline Alkaline phosphatase $(\mathrm{U} / \mathrm{L})$ & $123.00 \pm 2.00$ & $127.00 \pm 4.58$ & $118.00 \pm 4.16$ & $118.00 \pm 3.46$ \\
\hline Total protein $(\mathrm{g} / \mathrm{L})$ & $68.96 \pm 0.97$ & $68.00 \pm 3.36$ & $68.70 \pm 5.46$ & $70.26 \pm 1.32$ \\
\hline Albumin $(\mathrm{g} / \mathrm{L})$ & $34.86 \pm 0.37$ & $34.50 \pm 1.90$ & $35.26 \pm 2.70$ & $34.26 \pm 2.77$ \\
\hline Total bilirubin $(\mu \mathrm{mol} / \mathrm{L})$ & $5.16 \pm 0.41$ & $5.03 \pm 0.89$ & $4.90 \pm 0.26$ & $4.93 \pm 0.49$ \\
\hline Creatinine $(\mathrm{mmol} / \mathrm{L})$ & $50.00 \pm 6.24$ & $51.33 \pm 2.51$ & $46.00 \pm 4.58$ & $43.66 \pm 3.51$ \\
\hline Urea $(\mathrm{mmol} / \mathrm{L})$ & $5.83 \pm 0.60$ & $6.20 \pm 0.55$ & $5.80 \pm 0.36$ & $5.76 \pm 0.37$ \\
\hline Cholesterol $(\mathrm{mmol} / \mathrm{L})$ & $2.56 \pm 0.15$ & $2.23 \pm 0.05^{*}$ & $2.53 \pm 0.15$ & $2.30 \pm 0.10$ \\
\hline Triglycerides $(\mathrm{U} / \mathrm{L})$ & $0.99 \pm 0.01$ & $0.98 \pm 0.01$ & $0.97 \pm 0.13$ & $1.03 \pm 0.16$ \\
\hline
\end{tabular}

${ }^{1}$ Values are mean \pm SD from 6 rats per group $(\mathrm{n}=6)$.

*Significant difference from control $(P<0.05)$.

treated samples demonstrated healthy alveolar tissue that was thinly layered to facilitate gas exchange and was infiltrated with lymphocytes to fight off airborne microbes. For liver, both control and treated samples showed healthy lobular structure with the central vein surrounded by hepatocytes (liver single cell unit) that radiated outwards. Kupffer cells were identified as large, distinct nuclei located at the periphery of sinusoid. For kidney, we observed the renal corpuscle (tuft ball-shaped unit) with complete, intact Bowman's capsule and glomerulus, along with convoluted tubules (rod or spherical in shape). We found no vacuolation of the glomerulus, expansion of Bowman's space, or formation of cysts, indicating normal kidney histology. For testis, we observed a complete structure of seminiferous tubules with intact content in both control and treated rats. We found no disruption of sperm cells or irregular shape of membrane propria (membranous layer surrounding individual tubule). Finally, for ovary, we observed medulla with thick-walled blood vessels. No ovaries showed toxic signs such as lymphocyte infiltration, oocyte necrosis, or unusual follicle atresia (breakdown of ovarian follicle). The findings from microscopic evaluation supported the nontoxic nature of
WPC hydrolysate in Wistar-Kyoto rats after $28 \mathrm{~d}$ of administration, supporting its potential as a functional ingredient.

\section{Efficacy of WPC Hydrolysate in Reducing BP in Spontaneously Hypertensive Rats}

We tested WPC hydrolysate in spontaneously hypertensive rats at 3 different concentrations (200, 400, and $800 \mathrm{mg} / \mathrm{kg}$ ) to measure in vivo BP-lowering efficacy. Figure 4 shows the systolic BP in spontaneously hypertensive rats measured at $0,2,4,6,8$, and $24 \mathrm{~h}$ after oral feeding. The aim of monitoring BP up to 24 $\mathrm{h}$ is to identify the extent of the BP-lowering effect before values return to baseline. At $24 \mathrm{~h}$, BP readings at all dosages returned to normal, indicating the good degradative and non-cumulative character of WPC hydrolysate after oral ingestion. The negative control group, fed distilled water, showed no significant changes in BP over $24 \mathrm{~h}$, and the positive control group, fed captopril (a well-known antihypertensive drug), showed significant BP-lowering effect after administration. All treatment samples showed significant $\mathrm{BP}$ reduction compared with baseline $(213.5 \mathrm{~mm} \mathrm{Hg})$; we recorded 

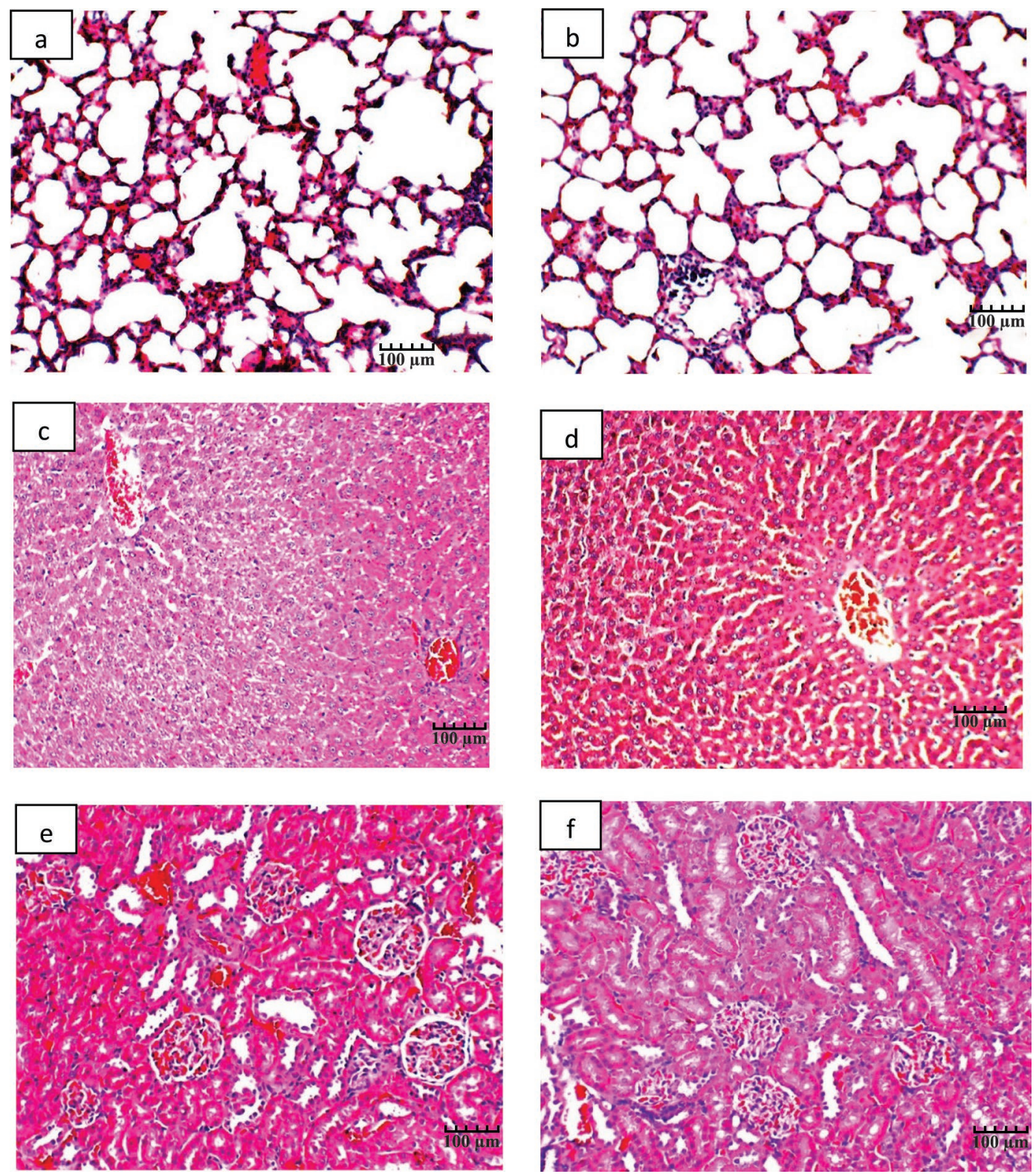

Figure 2. Light photomicrographs of (a) lung, (c) liver, and (e) kidney cortex for control, and (b) lung, (d) liver, and (f) kidney cortex (20× magnification; hematoxylin and eosin stain) for Wistar-Kyoto rats administered $800 \mathrm{mg} / \mathrm{kg}$ whey protein concentrate hydrolysate. Scale bars represent $100 \mu \mathrm{m}$ in each panel.

maximum reductions of $29.9 \mathrm{~mm} \mathrm{Hg}$ for the $200 \mathrm{mg} / \mathrm{kg}$ group, $47.8 \mathrm{~mm} \mathrm{Hg}$ for the $400 \mathrm{mg} / \mathrm{kg}$ group, and 57.2 $\mathrm{mmHg}$ for the $800 \mathrm{mg} / \mathrm{kg}$ group. These BP reductions were dose-dependent: a igher WPC hydrolysate concentration contributed to a stronger $\mathrm{BP}$-lowering effect.

The BP-lowering efficacy of dairy products, particularly from milk proteins, has been reported in the literature. For instance, bovine casein hydrolysate has been shown to reduce BP in spontaneously hypertensive rat up to $42 \mathrm{~mm} \mathrm{Hg}$ when dosed at $100 \mathrm{mg} / \mathrm{kg} \mathrm{BW}$ (Yamada et al., 2013), and fermented milk led to a BP reduction of 20 to $34 \mathrm{~mm} \mathrm{Hg}$ when dosed at $1.5 \mathrm{~mL}$ per rat (Muguerza et al., 2006). A study similar to the current study showed that bovine WPC hydrolysate, when produced using a crude enzyme extract from artichoke, led to a maximum BP reduction of $21 \mathrm{~mm}$ $\mathrm{Hg}$ in spontaneously hypertensive rats when fed at 400 $\mathrm{mg} / \mathrm{kg}$ (Tavares et al., 2012). At the same concentration, alcalase-hydrolyzed WPC showed a BP reduction of $47.8 \mathrm{~mm} \mathrm{Hg}$ in the current study. This indicated a significant improvement in BP-lowering efficacy when WPC was treated with alcalase compared with arti- 
choke-derived enzymes. In another similar study, Wang et al. (2012) showed that alcalase-hydrolyzed WPC led to a maximum $\mathrm{BP}$ reduction of $37 \mathrm{~mm} \mathrm{Hg}$ when dosed at $240 \mathrm{mg} / \mathrm{kg}$, also showing improved antihypertensive activity compared with artichoke-derived enzymes. Enzyme selection plays a critical role in the release of antihypertensive peptides. For WPC, alcalase is a better choice for improving the release of these peptides.

\section{Characterization of ACE-Inhibitory Peptides Identified from WPC}

Physicochemical Properties. After we demonstrated the nontoxicity and BP-lowering efficacy of WPC hydrolysate in rat models, we subjected it to a sequencing protocol to look for potentially potent ACE-inhibitory peptides. We identified a total of 8 peptides from WPC: RHPEYAVSVLLR, GGAPPAGRL, GPPLPRL, ELKPTPEGDL, VLSELPEP, DAQSAPLRVY, RDMPIQAF, and LEQVLPRD. The physicochemical characteristics of these peptides are shown in Table 2. All peptides appeared as crystal white powder with good water solubility, consisted of 7 to 12 amino acids (oligopeptides), had an isoelectric point (pI) between 3.61 and 10.80, and a molecular weight of 748.92 to $1,439.67 \mathrm{Da}$. The net charge for peptides, measured at $\mathrm{pH} 7$, correlated well with their respective pI: neutral peptides showed a $\mathrm{pI}$ close to $\mathrm{pH}$ 7 , peptides with a negative charge showed $\mathrm{pI}$ values in the acidic region, and peptides with a positive charge showed $\mathrm{pI}$ values in the basic region. Instability index, which refers to the stability upon gastrointestinal digestion, is calculated using a mathematical formula that sums the instability weight value for dipeptide pairs in the sequence. Stability depends on the strength of the bond between amino acids (i.e., the smallest unit that contributes to a peptide bond). A peptide is considered stable if its instability index is less than 40 (Gasteiger et al., 2005). The current study found 3 stable peptides and 5 unstable peptides in WPC. However, instability does not dictate a peptide's final ACE-inhibitory functionality upon reaching target site. According to Fujita and Yoshikawa (1999), peptides that are susceptible to gastrointestinal digestion may have improved or reduced ACE inhibition, depending on the nature of the new compound formed after digestion.

$I C_{50}$ Values. In terms of $\mathrm{ACE}$ inhibition, $\mathrm{IC}_{50}$ denotes the peptide concentration required to exert half-
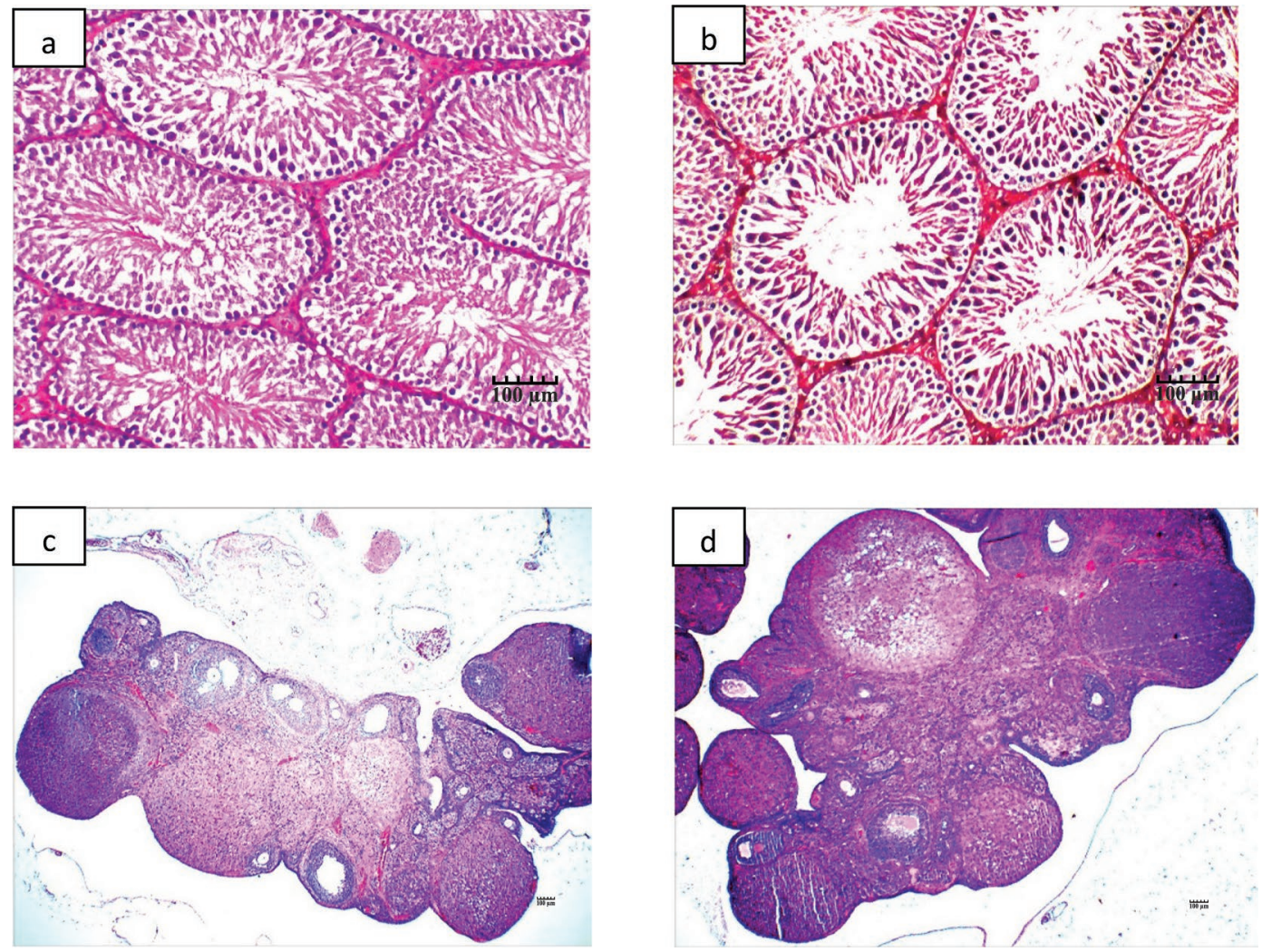

Figure 3. Light photomicrographs of male testis for (a) control and (b) treatment, viewed at 20× magnification (hematoxylin and eosin stain), and female ovary for (c) control and (d) treatment, viewed at $4 \times$ magnification (hematoxylin and eosin stain). Treatment groups were administered $800 \mathrm{mg} / \mathrm{kg}$ whey protein concentrate hydrolysate. Scale bars represent $100 \mu \mathrm{m}$ in each panel. 
Table 2. Eight peptide sequences identified from whey protein concentrate hydrolysate and their respective physicochemical characteristics ${ }^{1}$

\begin{tabular}{|c|c|c|c|c|c|c|}
\hline Peptide & $\begin{array}{l}\text { No. of } \\
\text { residues }\end{array}$ & Sequence & $\mathrm{pI}^{2}$ & Net charge ${ }^{3}$ at $\mathrm{pH} 7$ & $\begin{array}{c}\text { Molecular } \\
\text { weight (Da) }\end{array}$ & Instability index \\
\hline 1 & 12 & RHPEYAVSVLLR & 8.75 & +2 & $1,439.67$ & 73.08 (unstable) \\
\hline 2 & 9 & GGAPPAGRL & 9.75 & +1 & 794.90 & 77.37 (unstable) \\
\hline 4 & 10 & ELKPTPEGDL & 3.93 & -2 & $1,098.21$ & 10.53 (stable) \\
\hline 5 & 8 & VLSELPEP & 3.61 & -2 & 883.00 & 102.70 (unstable) \\
\hline 6 & 10 & DAQSAPLRVY & 6.23 & 0 & $1,119.23$ & 83.92 (unstable) \\
\hline
\end{tabular}

${ }^{1}$ Two online software programs were used to identify the sequences: ExPASyProtParam (http://web.expasy.org/protparam/) and GenScript peptide calculator (https://www.genscript.com/ssl-bin/site2/peptide_calculation.cgi).

${ }^{2}$ Isoelectric point.

${ }^{3}$ Net charge: 0 indicates neutral, + indicates basic, and - indicates acidic.

maximal inhibitory activity against $\mathrm{ACE}$. A high $\mathrm{IC}_{50}$ implies a peptide with low inhibitory power, and low $\mathrm{IC}_{50}$ implies a low inhibitory power. The $\mathrm{IC}_{50}$ for 8 peptides are reported in Table 3. Two peptides-peptides
5 (VLSELPEP, $\mathrm{IC}_{50}=0.049 \mathrm{~m} M$ ) and 8 (LEQVLPRD, $\left.\mathrm{IC}_{50}=0.043 \mathrm{~m} M\right)$ - showed the most prominent ACEinhibitory activity of the 8 WPC peptides. Factors affecting the peptides' potency included positioning of
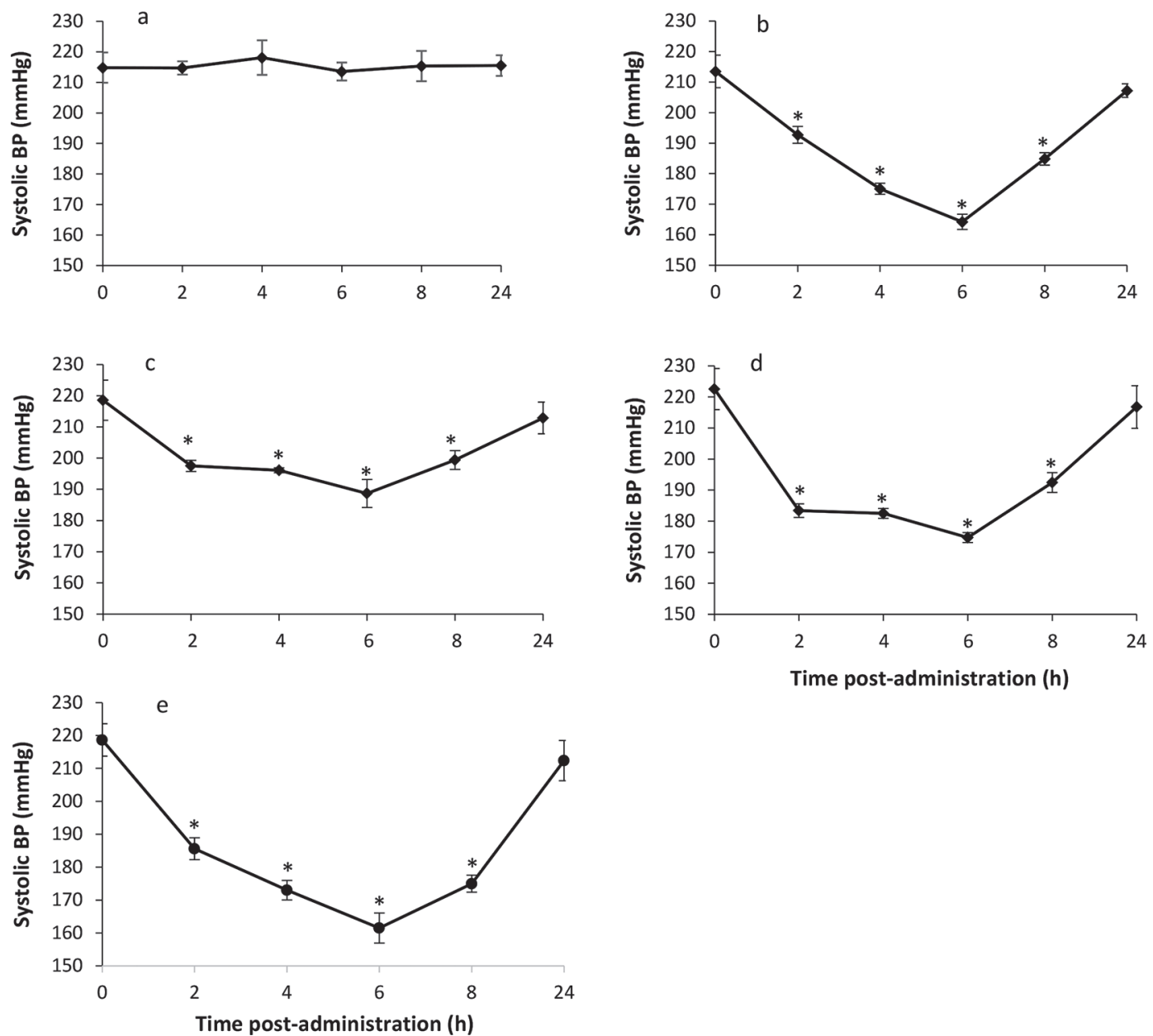

Figure 4. Systolic blood pressure (BP) in spontaneously hypertensive rats from (a) negative control (distilled water); (b) positive control (captopril $50 \mathrm{mg} / \mathrm{kg}$ ); and whey protein concentrate hydrolysate at (c) $200 \mathrm{mg} / \mathrm{kg}$, (d) $400 \mathrm{mg} / \mathrm{kg}$, and (e) $800 \mathrm{mg} / \mathrm{kg}$. Error bars represent standard deviations $(\mathrm{n}=6)$. ${ }^{*}$ Indicates significant lowering of BP compared with baseline $(0 \mathrm{~h} ; P<0.05)$. 
Table 3. Half-maximal inhibitory concentration $\left(\mathrm{IC}_{50}\right) \pm \mathrm{SD}$ for 8 whey protein concentrate peptides

\begin{tabular}{llr}
\hline Peptide & Sequence & \multicolumn{1}{c}{$\mathrm{IC}_{50}(\mathrm{~m} M)$} \\
\hline 1 & RHPEYAVSVLLR & $0.217 \pm 0.010$ \\
2 & GGAPPAGRL & $0.465 \pm 0.066$ \\
3 & GPPLPRL & $1.8 \pm 0.185$ \\
4 & ELKPTPEGDL & $0.412 \pm 0.093$ \\
5 & VLSELPEP & $0.049 \pm 0.004$ \\
6 & DAQSAPLRVY & $0.336 \pm 0.031$ \\
7 & RDMPIQAF & $0.194 \pm 0.013$ \\
8 & LEQVLPRD & $0.043 \pm 0.017$ \\
\hline
\end{tabular}

the amino acid within the sequence (C- or N-terminal), the types of amino acid present (hydrophobic vs. hydrophilic, aliphatic vs. aromatic) and peptide chain length. The presence of hydrophobic aliphatic amino acids such as leucine, isoleucine, and valine at the $\mathrm{N}$ terminal, and aromatic amino acids such as proline, tyrosine, and tryptophan at C-terminal, would contribute to ACE-inhibitory activity. Also, positively charged lysine and arginine at the C-terminal would improve inhibitory power (FitzGerald et al., 2004; Vermeirssen et al., 2004). The peptides VLSELPEP and LEQVL$\mathrm{PRD}$, showing the lowest $\mathrm{IC}_{50}$ (i.e., the strongest potency), contain valine and leucine at the N-terminal and proline and arginine at the C-terminal, which fit well with the structural requirements for ACE inhibition. Ibrahim et al. (2017) and Tavares et al. (2011), who worked on ACE-inhibitory peptides from goat and bovine whey protein, respectively, discovered several structural similarities with peptides obtained from the current work. For instance, QSLVYPFTGP reported by Ibrahim et al. (2017) demonstrated high amounts of hydrophobic amino acid and considerable amounts of proline residues, and KGYGGVSLPEW, DKVGINYW, and DAQSAPLRVY reported by Tavares et al. (2011) demonstrated aromatic character due to the presence of proline, tyrosine, and tryptophan at the C-terminal.

\section{CONCLUSIONS}

The current study evaluated the acute and subacute toxicity of WPC hydrolysate produced enzymatically using alcalase. Our acute study showed that the median lethal dose $\left(\mathrm{LD}_{50}\right)$ for WPC hydrolysate was more than $2,500 \mathrm{mg} / \mathrm{kg}$. Daily observation, organ weight, clinical chemistry, and histopathological evaluations from our subacute study showed no significant difference between rats treated with WPC hydrolysate and controls. We concluded that alcalase-hydrolyzed WPC is non-toxic. Following this, we assessed the BP-lowering efficacy of WPC hydrolysate in spontaneously hypertensive rats and the results showed a promising in vivo efficacy that was a significant improvement compared to previous work, supporting the potential of alcalasegenerated WPC hydrolysate as a safe, natural antihypertensive ingredient for incorporation into functional foods. We sequentially identified 8 peptides as marker peptides that contributed to ACE inhibition, of which 2 (VLSELPEP and LEQVLPRD) demonstrated $\mathrm{IC}_{50}<$ $0.05 \mathrm{~m} M$ and could be further evaluated.

\section{ACKNOWLEDGMENTS}

The authors express their sincere gratitude for the financial support from Universiti Putra Malaysia, Malaysia, under the university grant scheme GPIPS/2018/9643400 (Vote no.: 9643400). The authors have not stated any conflicts of interest.

\section{REFERENCES}

American Diabetes Association. 2018. 9. Cardiovascular disease and risk management: Standards of medical care in diabetes - 2018 . Diabetes Care 41(Suppl. 1):S86-S104. https://doi.org/10.2337/ dc18-S009.

Boehm, O., B. Zur, A. Koch, N. Tran, R. Freyenhagen, M. Hartmann, and K. Zacharowski. 2007. Clinical chemistry reference database for Wistar rats and C57/BL6 mice. Biol. Chem. 388:547-554. https://doi.org/10.1515/BC.2007.061.

Boland, M. 2011. Whey proteins. Pages 30-55 in Handbook of Food Proteins. G. O. Philips and P. A. Williams, ed. Woodhead Publishing Ltd., Cambridge, UK.

Boyacı, D., F. Korel, and A. Yemenicioğlu. 2016. Development of activate-at-home-type edible antimicrobial films: An example $\mathrm{pH}-$ triggering mechanism formed for smoked salmon slices using lysozyme in whey protein films. Food Hydrocoll. 60:170-178. https:// doi.org/10.1016/j.foodhyd.2016.03.032.

Cummings, B. S., L. P. Wills, and R. G. Schnellmann. 2012. Measurement of cell death in mammalian cells. Curr. Protoc. Pharmacol. $56: 12.8 .1-12.8 .24$

Cushman, D. W., and H. Cheung. 1971. Spectrophotometric assay and properties of the angiotensin-converting enzyme of rabbit lung. Biochem. Pharmacol. 20:1637-1648. https://doi.org/10.1016/0006 -2952(71)90292-9.

Ferreira, I., O. Pinho, M. Mota, P. Tavares, A. Pereira, M. Goncalves, D. Torres, C. Rocha, and J. Teixeira. 2007. Preparation of ingredients containing an ACE-inhibitory peptide by tryptic hydrolysis of whey protein concentrates. Int. Dairy J. 17:481-487. https://doi .org/10.1016/j.idairyj.2006.06.023.

FitzGerald, R. J., B. A. Murray, and D. J. Walsh. 2004. Hypotensive peptides from milk proteins. J. Nutr. 134:980S-988S. https://doi .org/10.1093/jn/134.4.980S.

Fuglsang, A., F. P. Rattray, D. Nilsson, and N. C. Nyborg. 2003. Lactic acid bacteria: Inhibition of angiotensin converting enzyme in vitro and in vivo. Antonie van Leeuwenhoek 83:27-34. https://doi .org/10.1023/A:1022993905778.

Fujita, H., and M. Yoshikawa. 1999. LKPNM: A prodrug-type ACEinhibitory peptide derived from fish protein. Immunopharmacology 44:123-127. https://doi.org/10.1016/S0162-3109(99)00118-6.

Gasteiger, E., C. Hoogland, A. Gattiker, S. Duvaud, M. R. Wilkins, R. D. Appel, and A. Bairoch. 2005. Protein identification and analysis tools on the ExPASy server. Pages 571-607 in The Proteomics Protocols Handbook. J. M. Walker, ed. Humana Press, Totowa, NJ.

Giknis, M., and C. Clifford. 2008. Clinical Laboratory Parameters for Crl: WI(Han) Rats. Charles River Laboratories, Wilmington, MA.

Greaves, P. 2012. Histopathology of Preclinical Toxicity Studies: Interpretation and Relevance in Drug Safety Evaluation. Academic Press, London, UK. 
Guo, Y., D. Pan, and M. Tanokura. 2009. Optimisation of hydrolysis conditions for the production of the angiotensin-I converting enzyme (ACE) inhibitory peptides from whey protein using response surface methodology. Food Chem. 114:328-333. https://doi.org/10 .1016/j.foodchem.2008.09.041.

Ibrahim, H. R., A. S. Ahmed, and T. Miyata. 2017. Novel angiotensinconverting enzyme inhibitory peptides from caseins and whey proteins of goat milk. J. Adv. Res. 8:63-71. https://doi.org/10.1016/ j.jare.2016.12.002.

Kearney, P. M., M. Whelton, K. Reynolds, P. Muntner, P. K. Whelton, and J. He. 2005. Global burden of hypertension: Analysis of worldwide data. Lancet 365:217-223. https://doi.org/10.1016/ S0140-6736(05)17741-1.

Lipnick, R. L., J. A. Cotruvo, R. N. Hill, R. D. Bruce, K. A. Stitzel, A. P. Walker, I. Chu, M. Goddard, L. Segal, J. A. Springer, and R. C. Myers. 1995. Comparison of the up-and-down, conventional $\mathrm{LD}_{50}$, and fixed-dose acute toxicity procedures. Food Chem. Toxicol. 33:223-231. https://doi.org/10.1016/0278-6915(94)00136-C.

Madureira, A. R., T. Tavares, A. M. P. Gomes, M. E. Pintado, and F. X. Malcata. 2010. Invited review: Physiological properties of bioactive peptides obtained from whey proteins. J. Dairy Sci. 93:437-455. https://doi.org/10.3168/jds.2009-2566.

Martínez, M. A., I. Ares, M. R. Martínez-Larrañaga, A. Anadón, V. Casado, L. Vazquez, D. Martin, G. Reglero, and C. Torres. 2018. Acute and repeated dose (28 days) oral safety studies of phosphatidyl-hydroxytyrosol. Food Chem. Toxicol. 120:462-471. https:// doi.org/10.1016/j.fct.2018.07.046.

Mekonnen, A., S. Tesfaye, S. G. Christos, K. Dires, T. Zenebe, N. Zegeye, Y. Shiferaw, and E. Lulekal. 2019. Evaluation of skin irritation and acute and subacute oral toxicity of Lavandula angustifolia essential oils in rabbit and mice. J. Toxicol. 2019:5979546. https:/ /doi.org/10.1155/2019/5979546.

Morais, H. A., M. P. C. Silvestre, M. R. Silva, V. D. M. Silva, M. A. Batista, A. C. Simões e Silva, and J. N. Silveira. 2015. Enzymatic hydrolysis of whey protein concentrate: Effect of enzyme type and enzyme:substrate ratio on peptide profile. J. Food Sci. Technol. 52:201-210. https://doi.org/10.1007/s13197-013-1005-z.

Muguerza, B., M. Ramos, E. Sánchez, M. Manso, M. Miguel, A. Aleixandre, M. Delgado, and I. Recio. 2006. Antihypertensive activity of milk fermented by Enterococcus faecalis strains isolated from raw milk. Int. Dairy J. 16:61-69. https://doi.org/10.1016/j.idairyj 2005.01.001

Olsen, M. H., S. Y. Angell, S. Asma, P. Boutouyrie, D. Burger, J. A. Chirinos, A. Damasceno, C. Delles, A.-P. Gimenez-Roqueplo, D. Hering, P. López-Jaramillo, F. Martinez, V. Perkovic, E. R. Rietzschel, G. Schillaci, A. E. Schutte, A. Scuteri, J. E. Sharman, K. Wachtell, and J. G. Wang. 2016. A call to action and a lifecourse strategy to address the global burden of raised blood pressure on current and future generations: The Lancet Commission on hypertension. Lancet 388:2665-2712. https://doi.org/10.1016/S0140 $-6736(16) 31134-5$.

OECD (Organisation for Economic Co-operation and Development). 2011. OECD guideline for testing of chemicals. Test Guideline 425: Acute oral toxicity (Up-and-down procedure). OECD, Paris, France.
OECD (Organization for Economic Cooperation and Development). 2008. OECD guideline for testing of chemicals. Test Guideline 407: Repeated dose 28-day oral toxicity study in rodents. OECD, Paris, France.

Porwal, M., N. Khan, and K. Maheshwari. 2017. Evaluation of acute and subacute oral toxicity induced by ethanolic extract of Marsdenia tenacissima leaves in experimental rats. Sci. Pharm. 85:E29. https://doi.org/10.3390/scipharm85030029.

Silveira, S. T., D. Martínez Maqueda, I. Recio, and B. Hernández Ledesma. 2013. Dipeptidyl peptidase-IV inhibitory peptides generated by tryptic hydrolysis of a whey protein concentrate rich in $\beta$-lactoglobulin. Food Chem. 141:1072-1077. https://doi.org/10 .1016/j.foodchem.2013.03.056.

Tavares, T., M. M. Contreras, M. Amorim, M. Pintado, I. Recio, and F. X. Malcata. 2011. Novel whey-derived peptides with inhibitory effect against angiotensin-converting enzyme: In vitro effect and stability to gastrointestinal enzymes. Peptides 32:1013-1019. https://doi.org/10.1016/j.peptides.2011.02.005.

Tavares, T., M. Á. Sevilla, M. J. Montero, R. Carrón, and F. X. Malcata. 2012. Acute effect of whey peptides upon blood pressure of hypertensive rats, and relationship with their angiotensin-converting enzyme inhibitory activity. Mol. Nutr. Food Res. 56:316-324. https://doi.org/10.1002/mnfr.201100381.

van der Ven, C., H. Gruppen, D. de Bont, and A. Voragen. 2002. Optimisation of the angiotensin converting enzyme inhibition by whey protein hydrolysates using response surface methodology. Int. Dairy J. 12:813-820. https://doi.org/10.1016/S0958 $-6946(02) 00077-8$.

Vermeirssen, V., A. van der Bent, J. Van Camp, A. van Amerongen, and W. Verstraete. 2004. A quantitative in silico analysis calculates the angiotensin I converting enzyme (ACE) inhibitory activity in pea and whey protein digests. Biochimie 86:231-239. https: //doi.org/10.1016/j.biochi.2004.01.003.

Wang, X., L. Wang, X. Cheng, J. Zhou, X. Tang, and X. Y. Mao. 2012. Hypertension-attenuating effect of whey protein hydrolysate on spontaneously hypertensive rats. Food Chem. 134:122-126. https: //doi.org/10.1016/j.foodchem.2012.02.074.

Wu, Q., X. Zhang, J. Jia, C. Kuang, and H. Yang. 2018. Effect of ultrasonic pretreatment on whey protein hydrolysis by alcalase: Thermodynamic parameters, physicochemical properties and bioactivities. Process Biochem. 67:46-54. https://doi.org/10.1016/j .procbio.2018.02.007.

Yamada, A., T. Sakurai, D. Ochi, E. Mitsuyama, K. Yamauchi, and F. Abe. 2013. Novel angiotensin I-converting enzyme inhibitory peptide derived from bovine casein. Food Chem. 141:3781-3789. https://doi.org/10.1016/j.foodchem.2013.06.089.

Zarei, M., B. Forghani, A. Ebrahimpour, A. Abdul-Hamid, F. Anwar, and N. Saari. 2015. In vitro and in vivo antihypertensive activity of palm kernel cake protein hydrolysates: Sequencing and characterization of potent bioactive peptides. Ind. Crops Prod. 76:112-120. https://doi.org/10.1016/j.indcrop.2015.06.040.

Zou, P., J. L. Wang, G. Q. He, and J. P. Wu. 2014. Purification, identification, and in vivo activity of angiotensin I-converting enzyme inhibitory peptide, from ribbonfish (Trichiurus haumela) backbone. J. Food Sci. 79:C1-C7. https://doi.org/10.1111/1750-3841.12269. 